\title{
Synthesis and properties of thio-containing poly(ether ether ketone)s
}

\author{
Yen-Zen Wang, ${ }^{1 *}$ Chih-Hung Lin, ${ }^{2}$ Bor-Wen Chan ${ }^{3}$ and Kuo-Huang Hsieh ${ }^{3}$ \\ ${ }^{1}$ Department of Chemical Engineering, National Yunlin University of Science and Technology, Yunlin 640, Taiwan \\ ${ }^{2}$ Graduate School of Engineering Science and Technology (Doctoral Program), National Yunlin University of Science and Technology, \\ Yunlin 640, Taiwan \\ ${ }^{3}$ Department of Chemical Engineering, National Taiwan University, Taipei 106, Taiwan
}

\begin{abstract}
A series of thio-containing poly(ether ether ketone) (PEESK) polymers was synthesized by the introduction of thio groups from $4,4^{\prime}$ thiodiphenol (TDP) into the poly(ether ether ketone) (PEEK) structure via reaction between the phenol and aromatic fluoride groups. The effect of the thio groups on the properties of the PEESK materials was investigated. Differential scanning calorimetry (DSC) analysis and X-ray diffraction (XRD) patterns show a depression in the crystallinity of the PEESKs with incorporation of the content of thio groups in the backbones. The crystalline structure was identified as an orthorhombic structure with lattice constants of $a=7.52 \AA, b=5.86 \AA$ and $c=10.24 \AA$ for all crystallizable PEESKs. The crystalline structures of the thio-containing PEEK polymers were the same as that of the neat PEEK, which means the thio-containing block in the whole thio-containing PEEK molecule is almost excluded from the crystalline structure and the crystals are completely formed by 'non-thio' blocks only. Due to the glass transition temperature $\left(T_{\mathrm{g}}\right)$ and melting temperature $\left(T_{\mathrm{m}}\right)$ depression with increase in the TDP content in the reaction system, the processability of the resultant thio-containing PEEKs could be effectively improved.

(c) 2004 Society of Chemical Industry
\end{abstract}

Keywords: poly(ether ether ketone); thiodiphenol; poly(ether ether sulfide ketone); physical properties; crystallinity

\section{INTRODUCTION}

Poly(ether ether ketone) (PEEK) is a semicrystalline high-performance thermoplastic polymer with a glass transition temperature $\left(T_{\mathrm{g}}\right)$ of $143^{\circ} \mathrm{C}$ and a melting point $\left(T_{\mathrm{m}}\right)$ of the main crystallites of $334^{\circ} \mathrm{C}$ and is well known for its high chemical resistance, excellent heat resistance and good mechanical behaviour. ${ }^{1,2}$ These excellent properties make PEEK an attractive high-performance polymer, potentially used as a structural adhesive and as a composite matrix. Due to its high melting point and high glass transition temperature, , $^{3,4}$ a number of modifications have been adopted to reduce the processing temperature, such as softening the backbone and lowering the $T_{\mathrm{m}}$ of the PEEK. ${ }^{5-16}$ As the carbonyl groups were replaced by sulfoxide groups in the PEEK backbone, this subsequently resulted in a total loss of the crystalline structure. ${ }^{17}$ However, the $T_{\mathrm{g}}$ of the modified PEEK is very high $\left(178^{\circ} \mathrm{C}\right)$ and the polymer is still difficult to process. A further modification was made by replacing the sulfoxide groups with sulfide groups. The modified PEEK regained a crystalline structure with a $T_{\mathrm{m}}$ of $251^{\circ} \mathrm{C}$ and a $T_{\mathrm{g}}$ of $102^{\circ} \mathrm{C}$. Wang and Roovers synthesized a modified PEEK by introducing aldehyde and carboxylic acid groups into the backbone of PEEK to improve the processability for membrane applications. ${ }^{18}$ Brink et al. prepared poly[(pyridine ether)-co-(ether ether ketone)] to form a complex with hydrochloric acid in order to suspend the modified PEEK in water. ${ }^{19}$ However, this synthesis procedure is fairly tedious. The effects of the carbonyl and ether groups on the shifts of the $T_{\mathrm{g}}$ of PEEK have been studied. ${ }^{9}$ The ether-linked aromatic polymer, poly(phenylene oxide) (PPO), has a $T_{\mathrm{g}}$ at $85^{\circ} \mathrm{C}$, while the $T_{\mathrm{g}}$ increased to $154^{\circ} \mathrm{C}$ as carbonyl groups were inserted into the etherlinked backbone to form poly(ether ketone) (PEK) polymer. As more ether groups were introduced to form the PEEK backbone, the $T_{\mathrm{g}}$ shifted to a lower temperature of $144^{\circ} \mathrm{C}$. In this present paper, a modified PEEKs, based on the introduction of thio groups into the backbone in order to reduce the $T_{\mathrm{g}}$ and crystallinity of the parent PEEK, have been prepared. The effect of the introduced thio groups on the crystalline characteristics, degradation temperatures, thermomechanical and processing temperatures of the resultant PEEKs have been investigated.

* Correspondence to: Yen-Zen Wang, Department of Chemical Engineering, National Yunlin University of Science and Technology, Yunlin 640, Taiwan

E-mail: wangzen@yuntech.edu.tw

(Received 8 October 2002; revised version received 26 March 2003; accepted 10 April 2003) 


\section{EXPERIMENTAL} Materials

Hydroquinone, 4,4'-difluorobenzophenone, $4,4^{\prime}$-thiodiphenol, diphenylsulfone, sodium carbonate, potassium carbonate, acetone and methanol were used without any further purification. Poly(phenylene sulfide) and poly(phenylene oxide), purchased from ACROS and GE, respectively, were used as model samples.

\section{Synthesis of PEEK}

Hydroquinone (HQ) was mixed with difluorobenzophenone (DFBP) in diphenylsulfone solvent under nitrogen gas in a reaction kettle. The reactor was preheated to $180^{\circ} \mathrm{C}$, followed by the addition of a mixture of sodium and potassium carbonate salts. The temperature was then increased to $200^{\circ} \mathrm{C}$ for reaction to take place over about $30 \mathrm{~min}$. The reaction was allowed to proceed for one more hour at $250^{\circ} \mathrm{C}$, and then the temperature was increased to $320^{\circ} \mathrm{C}$ to complete the reaction. The resultant polymer solution became a hard solid when cooled. The trapped solvent, monomer, solvent and salt were removed by washing the resultant polymer, followed by extraction with acetone, deionized water and methanol, in turn. Finally, the sample was dried in an oven at $180^{\circ} \mathrm{C}$ for $10 \mathrm{~h}$.

\section{Synthesis of poly(ether ether sulfide ketone)}

An equimolar mixture of TDP and DFBP was added to the reactor under a nitrogen gas atmosphere. The reaction conditions were the same as those used for the synthesis of PEEK described above.

\section{Synthesis of thio-containing PEEK polymer (PEESK)}

Various molar ratios of HQ/TDP mixtures were added to react with DFBP (in equimolar ratio) in the reactor. The reaction conditions were the same as those used in the synthesis of PEEK. The latter was therefore modified by various molar fractions of thio groups as a result of introducing TDP into the molecular chain.

\section{Testing methods}

Fourier-transform infrared (FTIR) spectra of the samples were obtained from a Bi-Rad FT-40 spectrophotometer. Sixty four scans were signalaveraged at a resolution of $2 \mathrm{~cm}^{-1}$ from 400 to $4000 \mathrm{~cm}^{-1}$. Testing samples were prepared by cryogenically grinding the synthesized polymers with $\mathrm{KBr}$ and then compressing the mixtures to form disks.

Differential scanning calorimetry (DSC) was carried out by using a DuPont 2000 calorimeter, measuring from room temperature to $300^{\circ} \mathrm{C}$ at a scanning rate of $10^{\circ} \mathrm{C} / \mathrm{min}$.

Thermogravimetric analysis (TGA) of the samples was carried out by using a DuPont 951 instrument. The analysis was performed at a heating rate of $10^{\circ} \mathrm{C} \mathrm{min}^{-1}$, under a nitrogen atmosphere.
Dynamical mechanical analysis (DMA) was performed on a DuPont 983 machine with an operating temperature ranging from room temperature to $275^{\circ} \mathrm{C}$. The frequency was fixed at $1 \mathrm{~Hz}$ and the heating rate was set at $5^{\circ} \mathrm{C} \mathrm{min}{ }^{-1}$. A sample size of approximately $50 \times 10 \times 2 \mathrm{~mm}$ was used.

Wide-angle X-ray diffraction (WAXD) measurements were performed at room temperature with powder specimens on a Philips PW 1840 wide-angle Xray diffractometer, using Ni-filtered $\mathrm{Cu} \mathrm{K} \alpha$ radiation. The diffraction angle was varied from 5 to $70^{\circ}$.

\section{RESULTS AND DISCUSSION Characterization of thio-containing poly(ether ether ketone)s}

The synthesized poly(ether ether ketone) (PEEK) and thio-containing PEEK polymers were characterized by FTIR spectroscopic analysis. The FTIR spectra of the PEEK and thio-containing PEEK polymers with various percentages of TDP incorporated into the main chains are shown in Figure 1. The FTIR spectrum of the PEEK was consistent with the expected structure. Spectral comparison of the PEEK and PEESK materials is illustrated in Figure 1, where significant differences were observed for the peaks at 530 and $510 \mathrm{~cm}^{-1}$. It can be seen that the apparent difference in chemical structure between the PEEK and PEESK materials is in the $\mathrm{C}-\mathrm{O}-\mathrm{C}$ and $\mathrm{C}-\mathrm{S}-\mathrm{C}$ groups. To characterize the PEESK structure, FTIR spectra of the neat poly (phenylene sulfide) (PPS) and poly(phenylene oxide) (PPO) were used as model compounds to distinguish the absorption modes of the PEEK and thio-containing PEEK polymers. The FTIR spectra of PPS and PPO demonstrate different absorption positions for the rocking modes of the ether and sulfide groups from 400 to $590 \mathrm{~cm}^{-1}$. It was found that the peaks at 510 and $480 \mathrm{~cm}^{-1}$ correspond to the rocking absorption peaks of the $\mathrm{C}-\mathrm{O}-\mathrm{C}$ and $\mathrm{C}-\mathrm{S}-\mathrm{C}$ groups, respectively. Based on the FTIR spectra of the model compounds, the $\mathrm{C}-\mathrm{S}-\mathrm{C}$ intensity of the thio-containing PEEK polymers will be increased by the introduction of thio groups into the backbones. As shown in Figure 1, the sulfur group peak at $510 \mathrm{~cm}^{-1}$ increases significantly with an increase in the amount of introduced TDP. This rises with the increase in thio group content in the resultant polymers.

\section{X-ray diffraction analysis}

Wide-angle X-ray diffraction (WAXD) was used to analyse the crystal structures and calculate the crystallinities of the thio-containing PEEK polymers. Crystallinities were estimated by integrating the areas of the diffraction peaks divided by the summation area under the crystallized peak and the amorphous area. Amorphous PEEK can be obtained by quenching the molten PEEK into liquid nitrogen. The crystal structure, morphology, crystallization and melting behaviour of PEEK have been extensively studied by several authors. ${ }^{20-28}$ PEEK was found to exhibit 


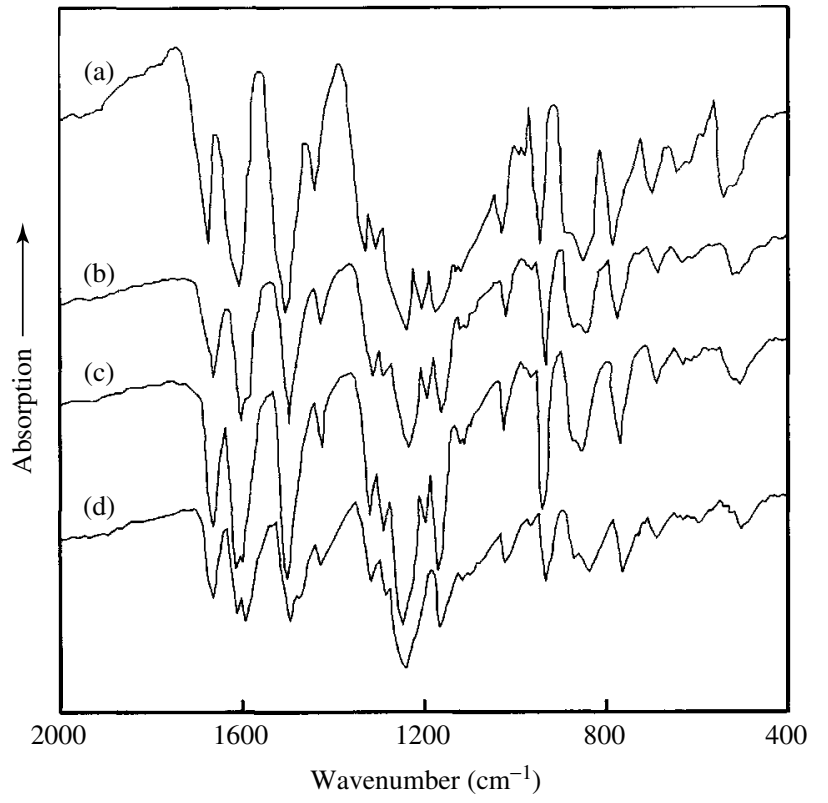

Figure 1. FTIR spectra of thio-containing PEEK polymers with various TDP/HQ ratios: (a) 0/100; (b) 30/70; (c) 50/50; (d) 100/0.

crystallization behaviour and a spherulitic growth similar to poly(ethylene terephthalate). ${ }^{20}$ The crystal structure of PEEK is similar to that of $\operatorname{poly}(p-$ phenylene oxide), with the orthorhombic unit cell of a PEEK crystal having lattice constants of $a, b$ and $c$ in the ranges of 7.75-7.78, 5.89-5.92 and 9.88-10.06 $\AA$, respectively. In particular, the unit cell dimensions are known to depend on the temperature of crystallization and/or annealing. ${ }^{21-22} \mathrm{X}$-ray diffraction patterns of the thio-containing PEEK polymers and the calculated crystallinities of these polymers are shown in Figure 2 and Figure 3, respectively. As can be observed in Figure 2, it was found that the X-ray diffraction patterns of the thio-containing PEEK polymers were almost identical to that of the neat PEEK, which means the incorporation of the TDP only creates more amorphous regions and the thio groups do not take part in the formation of any crystalline structure. Meanwhile, the crystallinity as a function of composition, which is shown in Figure 3, demonstrates a decreasing trend after the introduction of TDP, with no crystallinity being found after the TDP content reaches $80 \%$. Therefore, the crystallinities of the polymers illustrate a depression, since the flexible $\mathrm{C}-\mathrm{S}-\mathrm{C}$ bond mainly provides a freer rotation around the main axis, hence resulting in a loose conformation when compared to that of the ether-linked group. This shows that the thiocontaining blocks are excluded from the growth of the PEEK crystal. Changes in such effects might induce more gauche conformations, hence resulting in loop defects outside of the lamellae, which would then reduce the crystallinities of the resultant polymers.

Furthermore, the major diffraction peaks of the thio-containing PEEK polymers were identified as representing the (110), (111), (102), (200), (211) and (202) planes. The corresponding $d$-spacings are

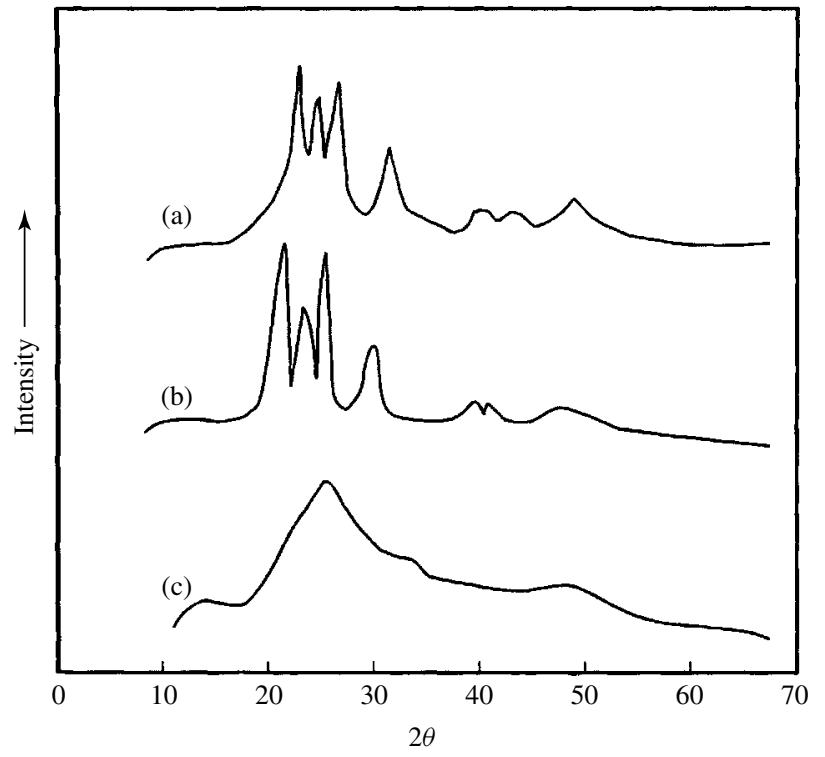

Figure 2. X-ray diffraction patterns of thio-containing PEEK polymers with various TDP/HQ ratios: (a) 0/100; (b) 50/50; (c) 100/0.

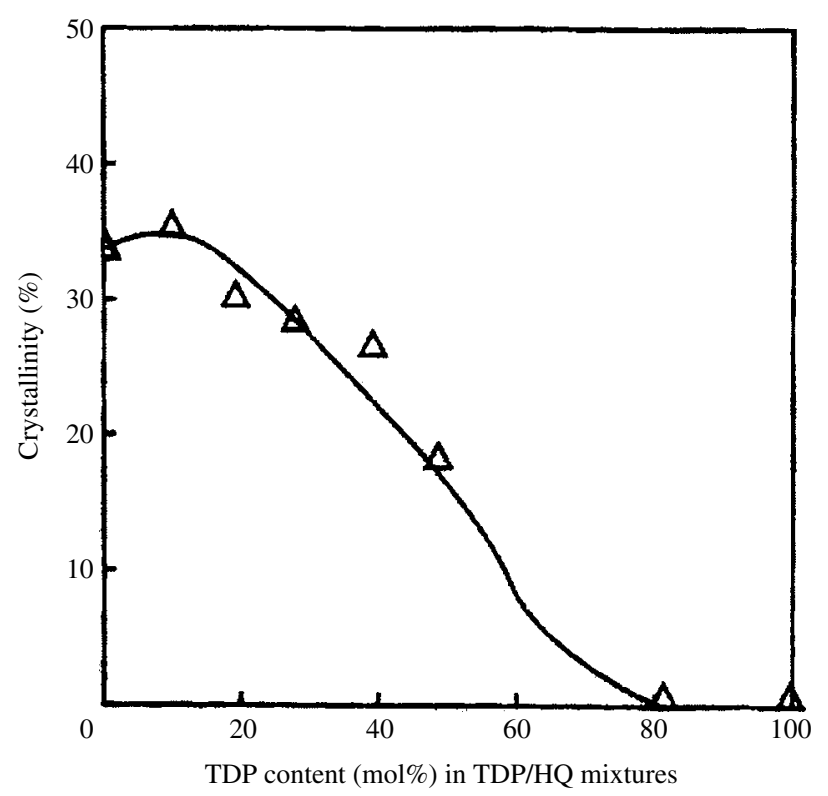

Figure 3. Dependence of crystallinity of thio-containing PEEK polymers on the TDP content (mol\%) in the TDP/HQ mixtures.

$4.62,4.21,4.23,3.76,3.02$ and $3.03 \AA$, respectively. According to these characteristic diffraction peaks, the lattice is confirmed as being an orthorhombic system, with calculated lattice constants of 7.52, 5.86 and $10.24 \AA$ for the $a, b$, and $c$ axes, respectively. For these polymers, the benzene rings, separated by functional groups, always locate in the orthorhombic lattice as they are crystallized. In such a lattice, two chains are included in the structure and the $c$-axis (chain axis) includes two benzene rings and two functional groups (ether and carbonyl). The $a$-axis and $b$-axis are the distances between the individual chains in the $X$ - and $Y$-co-ordinations. The structure diagram of the cell of the thio-containing PEEK is illustrated in Figure 4, which can easily be seen 


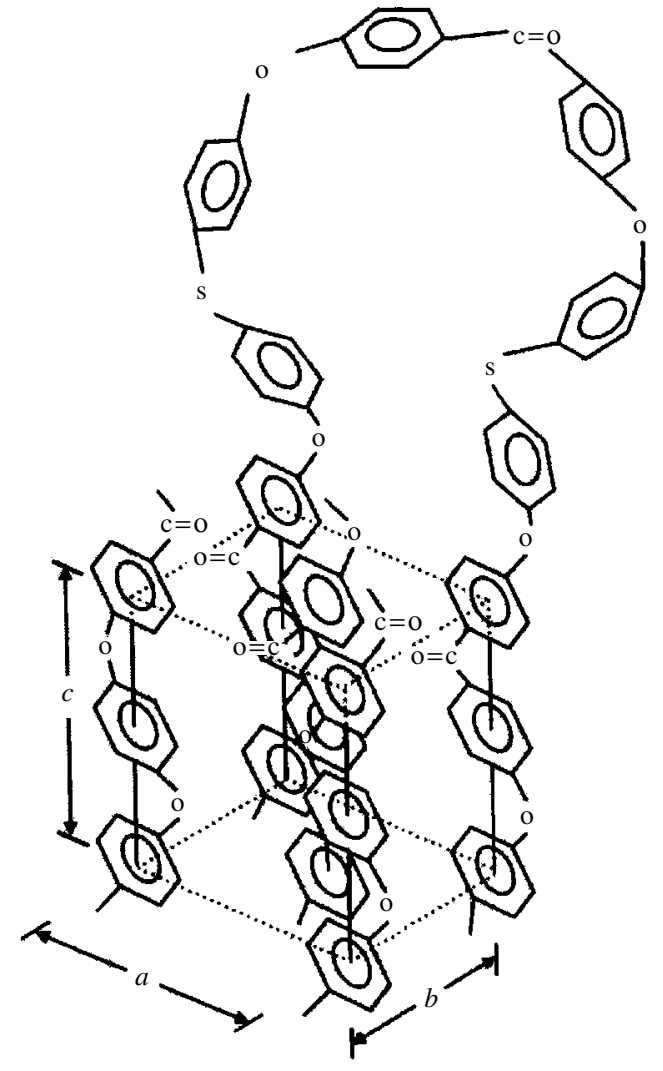

Figure 4. Schematic diagram of the crystalline structure of thio-containing PEEK.

Table 1. Lattice constants $(\AA)$ and bond angles (degrees) of PEEK-related polymers

\begin{tabular}{lccrc}
\hline Designation & $a$ & $b$ & $c$ & $\delta^{2 a}$ \\
\hline PPO & 8.07 & 5.54 & 9.72 & 124 \\
PPS & 8.67 & 5.61 & 10.26 & 110 \\
PEK & 7.63 & 5.96 & 10.00 & 123 \\
PEEK & 7.52 & 5.86 & 10.24 & - \\
PEEK & 7.78 & 5.92 & 10.06 & - \\
PEEEK & 7.52 & 5.86 & 10.24 & - \\
PEESK & 7.52 & 5.86 & 10.24 & - \\
\hline
\end{tabular}

${ }^{a}$ Bond angle of $\mathrm{C}-\mathrm{O}-\mathrm{C}$ or $\mathrm{C}-\mathrm{S}-\mathrm{C}{ }^{3}$

b Synthesized material. ${ }^{29}$

${ }^{\mathrm{c}}$ From theoretical calculations. ${ }^{30}$

to be an orthorhombic arrangement of molecules. The lattice constants and bond angles of the PEEKrelated polymers are presented in Table 1 . The lattice constants of the thio-containing PEEK are very close to the values of the PEEK-related polymers. The similar lattice and the decreasing crystallinity of the thiocontaining PEEK materials demonstrate that the point of introduction of the sulfide group was not located in the lattice and it therefore destroyed the regular crystal structure. The obtained X-ray diffraction data illustrate simply the structure of the crystalline region without any sulfide groups in the lattice. Otherwise, when compared with the unit cell of neat PEEK in the published literature, ${ }^{30}$ the calculated $c$-constants of the thio-containing PEEK polymers are slightly larger, hence indicating that the thio-containing blocks, although outside the crystallites, have an extended effect on the main chain.

\section{Differential Scanning Calorimetric Analysis}

As shown in Figure 5, the melting points $\left(T_{\mathrm{m}} \mathrm{s}\right)$ of the thio-containing PEEK materials gradually decreased and then disappeared with an increase in the TDP content in the TDP/HQ mixtures. The $T_{\mathrm{m}}$ and $T_{\mathrm{g}}$ values of the PEEK-related polymers are listed in Table 2. Figure 5 demonstrates that the $T_{\mathrm{m}}$ of the PEEK $\left(352^{\circ} \mathrm{C}\right)$ can be reduced to $237^{\circ} \mathrm{C}$ when the TDP/HQ ratio is $50 / 50$, which proved that the thio groups were inserted to form the thio-ketone polymers. As the TDP/HQ ratio in the PEESKs approaches $100 \%$, the resultant polymers are not able to crystallize, as shown in Figure 5. This might be attributed to two effects: the more flexible nature of the thio groups when compared to that of the ethergroup and the size of the sulfur atom being much larger than that of the oxygen one, which cannot 'match' the neat PEEK crystal structure and therefore reduces the crystallinity and its melting point. It can be concluded

Table 2. Thermal properties of thio-containing PEEK polymers

\begin{tabular}{lcc}
\hline TDP/HQ ratio & $T_{\mathrm{g}}\left({ }^{\circ} \mathrm{C}\right)^{\mathrm{a}}$ & $T_{\mathrm{m}}\left({ }^{\circ} \mathrm{C}\right)^{\mathrm{b}}$ \\
\hline O/100 (PEEK) & 163 & 352 \\
10/90 & 155 & 350 \\
$20 / 80$ & 140 & 302 \\
$30 / 70$ & 132 & 261 \\
$50 / 50$ & 120 & 237 \\
$80 / 20$ & 114 & - \\
$100 / 0$ (PEESK) & 108 & - \\
\hline
\end{tabular}

${ }^{a}$ From DMA data.

${ }^{\mathrm{b}}$ From DSC data.

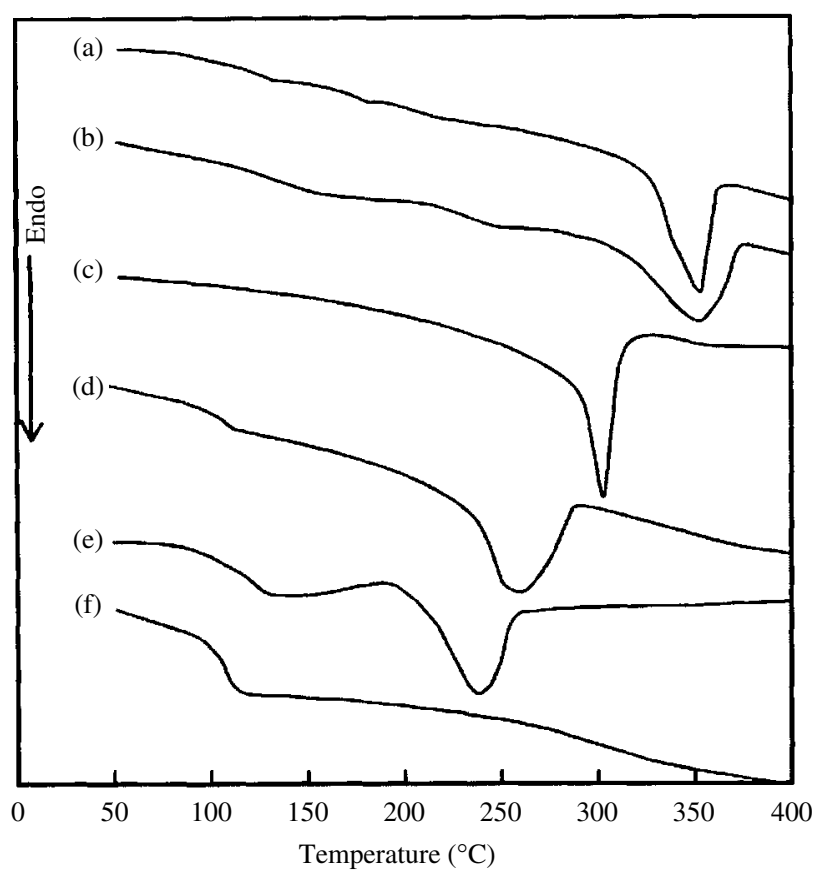

Figure 5. DSC thermograms of thio-containing PEEKs polymers with various TDP/HQ ratios: (a) 0/100; (b) 10/90; (c) 20/80; (d) 30/70; (e) $50 / 50$; (f) $100 / 0$. 


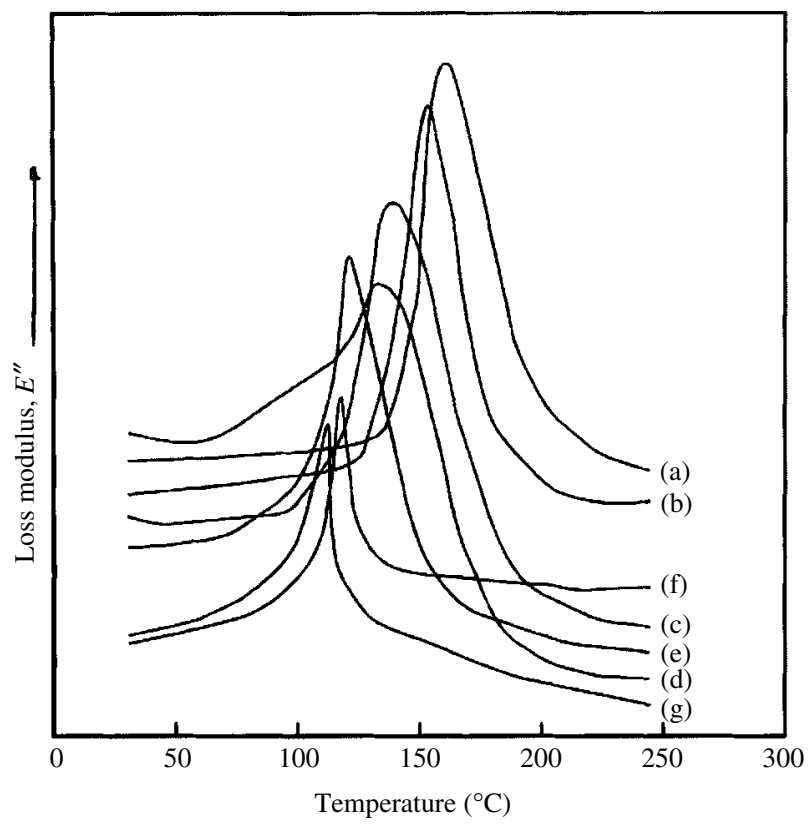

Figure 6. Loss modulus $\left(E^{\prime \prime}\right)$ plots of thio-containing PEEK polymers with various TDP/HQ ratios: (a) 0/100; (b) 10/90; (c) 20/80; (d) 30/70; (e) 50/50; (f) $80 / 20$; (g) 100/0.

that the depression in the $T_{\mathrm{m}}$ of the thio-containing PEEKs improves their processing properties. The $T_{\mathrm{g}}$ s cannot clearly be detected from DSC for thiocontaining PEEKs with high crystallinities. Therefore, the technique of DMA has been adopted for analysing the $T_{\mathrm{g}} \mathrm{s}$ of the thio-containing PEEKs. Plots of the temperature-dependence of the loss modulus $\left(E^{\prime \prime}\right)$ and storage modulus $\left(E^{\prime}\right)$ are shown in Figures 6 and 7, respectively. The peak temperatures of the $E^{\prime \prime}$ plots of the thio-containing PEEKs are considered as being the $T_{\mathrm{g}} \mathrm{s}$ of the resultant polymers and are given in Table 2. The apparent depressions in the $T_{\mathrm{g}}$ and $E^{\prime}$ values with an increase in TDP content were observed in the thio-containing PEEKs. Such depressions are due to the introduction of the more flexible $\mathrm{C}-\mathrm{S}-\mathrm{C}$ bonds into the resultant polymers.

The thermal stabilities of the thio-containing PEEK polymers were investigated by TGA. The resultant plots are illustrated in Figure 8. It can be seen that the synthesized PEEK was decomposed initially at $535^{\circ} \mathrm{C}$ with a $5 \mathrm{wt} \%$ loss, while the decomposition temperature of the thio-containing PEEK with 100 $\%$ TDP was $511^{\circ} \mathrm{C}$ (with $5 \mathrm{wt} \%$ loss). The thermal properties of the PEESKs were much superior to that of pure PPS $\left(497^{\circ} \mathrm{C}\right.$, with $5 \mathrm{wt} \%$ loss) and PPO $\left(452^{\circ} \mathrm{C}\right.$, with $5 \mathrm{wt} \%$ loss). The decomposition temperature $\left(T_{\mathrm{d}} \mathrm{s}\right)$ of the thio-containing PEEK polymers with various TDP contents are observed between 511 and $535^{\circ} \mathrm{C}$. The small variations in the $T_{\mathrm{d}} \mathrm{s}$ of the resultant polymers make the thio-containing PEEKs acceptable for heat-resistance applications.

\section{CONCLUSIONS}

The thio-group of TDP can be introduced into the ether-ether-ketone sequence in order to lower

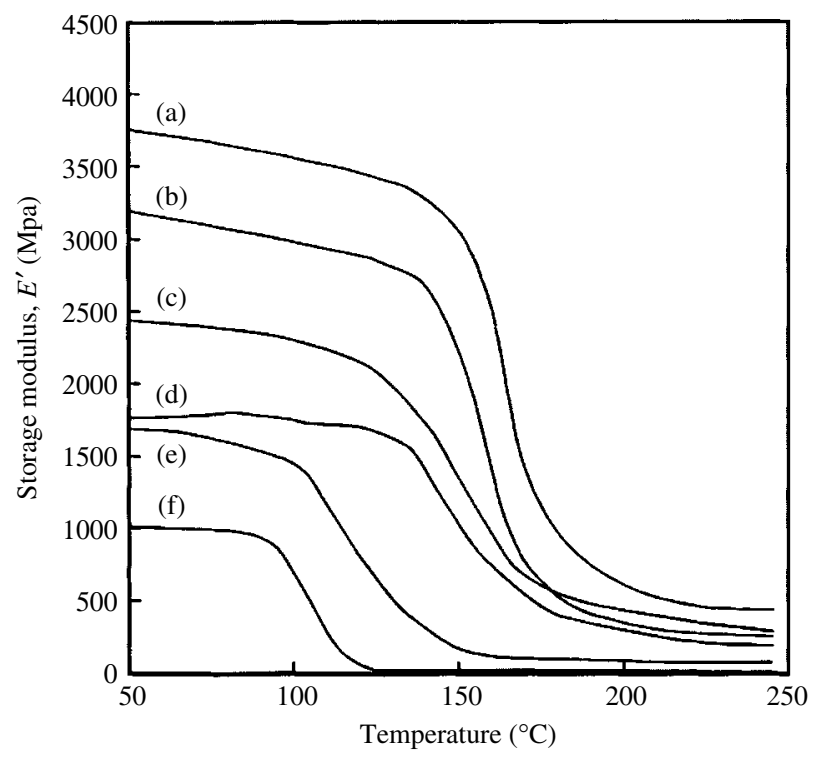

Figure 7. Storage modulus $\left(E^{\prime}\right)$ plots of thio-containing PEEK polymers with various TDP/HQ ratios: (a) 0/100; (b) 10/90; (c) 20/80; (d) 30/70; (e) 50/50; (f) 100/0.

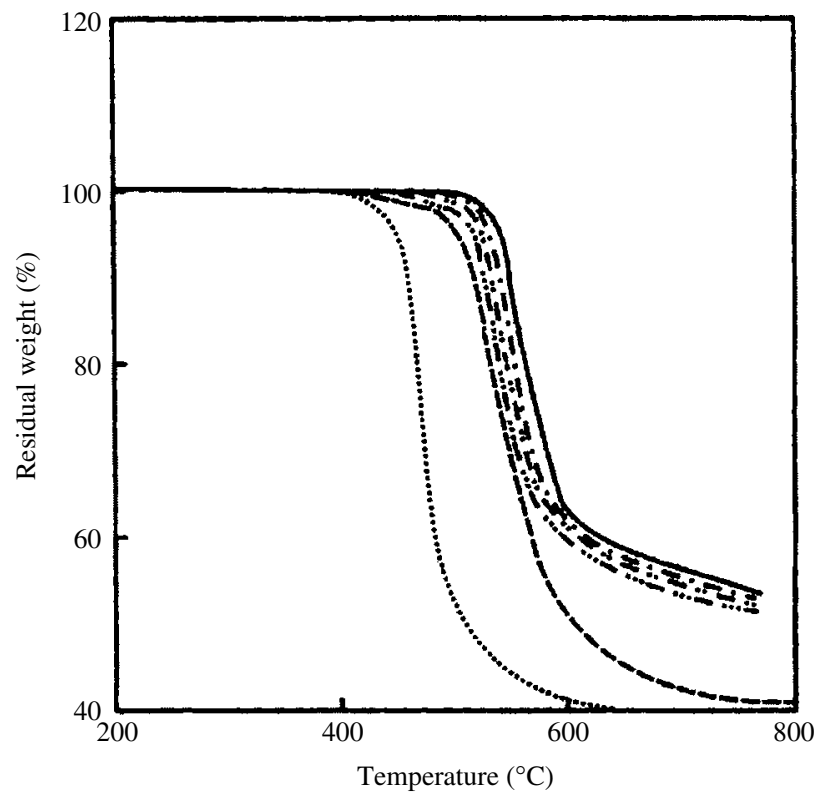

Figure 8. TGA plots of thio-containing PEEK polymers with various TDP/HQ ratios: (- $\longrightarrow$ neat PEEK; (-.-) 20/80; (-..-) 50/50; (-..-) 100/0; (- - - ) PPS; $(\cdots \cdots)$. PPO.

the processing temperature of the parent PEEK material. According to WAXD data, the resultant modified polymers, from PEEK to thio-containing PEEKs, exhibit orthorhombic structures with similar crystalline lattice constants. This is due to the flexible nature of the $\mathrm{C}-\mathrm{S}-\mathrm{C}$ thio linkage in the backbone, which mainly provides a free rotation around the main axis with increasing TDP content. The thio-containing PEEKs with greater thio linkages might induce more gauche conformations and increased loop defects of the lamellae, which would then decrease the thickness of the latter, therefore resulting in lower crystallinities and depressed melting points. 


\section{ACKNOWLEDGEMENTS}

The authors acknowledge with gratitude financial support from the National Science Council, Taiwan, Republic of China through Grant No. NSC 81-0405E002-08 and No. NSC 90-2216-E-224-001.

\section{REFERENCES}

1 Attwood TE, Dawson PC, Freeman JL, Hoy LRJ, Rose JB and Staniland PA, Polymer 22:1096 (1981).

2 Bishop MT, Karasz FE, Russo PS and Langley KH, Macromolecules 18:86 (1985).

3 Dawson PC and Blundell DJ, Polymer 21:577 (1980).

4 Mehmet-Alkan AA and Hay JN, Polymer 34:3529 (1993).

5 Johnson RN, Farnham AC, Clendinning RA, Hale WF and Merriam CN, f Polym Sci Polym Chem Ed 5:2357 (1967).

6 Chludzinski PJ, Fickett AP and Laconti AB, Am Chem Soc Div Polym Chem Polym Prepr 12:276 (1971).

7 Noshay A and Robeson LM, J Appl Polym Sci 20:1885 (1976).

8 Eisenberg A, Ions in Polymers, American Chemical Society, Washington, DC, USA (1980).

9 Attwood TE, Dawson PC, Freeman JL, Hoy LR, Rose JB and Staniland PA, Polymer 22:1076 (1981).

10 Johnson BL, Tran C, Yilgor I, Iqbal M, Wightman JP, Lloyd DR and McGrath JE, Am Chem Soc Div Polym chem Polym Prepr 24:31 (1983).
11 Jin X, Bishop MT, Ellis TS and Karasz FE, Br Polym $\mathcal{f}$ 17:4 (1985).

12 Clendinning RA, EP Patent 0226132 (1987).

13 Clendinning RA, US Patent 4786694 (1988).

14 Bourgeois Y, Charlier Y, Devaux J and Legras R, Polymer 37:5503 (1996).

15 Shibata M, Cao J and Yosomiya R, Polymer 38:3103 (1997).

16 Shu CF, Leu CM and Huang FY, Polymer 40:6591 (1999).

17 Babu JR, Konas M, Brink AE and Riffle JS, Polym Mater Sci Eng 68:99 (1993).

18 Wang F and Roovers J, Macromolecules 26:5295 (1993).

19 Brink AE, Lin MC and Riffle JS, Polym Mater Sci Eng 68:93 (1993).

20 Blundell DJ and Osborn BN, Polymer 24:953 (1983).

21 Blundell DJ, Polymer 28:2248 (1987).

22 Wakelyn NT, f Polym Sci, Polym Lett Ed 25:25 (1987).

23 Hay JN, Kemmish DJ and Lloyd JR, Polymer 30:489 (1989).

24 Cebe P and Hong SD, Polymer 27:1183 (1986).

25 Bassett DC, Olley RH and Al Raheil IAM, Polymer 29:1745 (1988).

26 Lee Y and Porter RS, Macromolecules 20:1336 (1987).

27 Lee Y, Porter RS and Lin JS, Macromolecules 22:1756 (1989).

28 Cao J, Su W and Wu Z, Polymer 37:4579 (1996).

29 Hsieh KH, Chern YC, Ho KS, Wang YZ, Chan BW and Chen LW, f Polym Res 3:83 (1996).

30 Rueda DR, Ania F, Richardson A, Ward IM and Balta Calleja FJ, Polymer Commun 24:2587 (1983). 